\section{Cureus}

\title{
Deteriorating Patient Scenario for Simulation-Based Training of Difficult Patient Encounters in the Emergency Room
}

\author{
Tia Renouf $^{1}$, Karen Mitchell ${ }^{2}$, Stuart Hollett ${ }^{2}$, Karen Angus ${ }^{3}$, Adam Dubrowski ${ }^{4}$ \\ 1. Emergency Medicine, Memorial University of Newfoundland 2. Clinical Learning and Simulation \\ Centre, Memorial University of Newfoundland 3. Discipline of Emergency Medicine, Memorial University \\ of Newfoundland 4. Emergency Medicine, Pediatrics, Memorial University of Newfoundland
}

$\square$ Corresponding author: Adam Dubrowski, adam.dubrowski@gmail.com Disclosures can be found in Additional Information at the end of the article

\section{Abstract}

The use of standardized patients [SP] in a deteriorating patient scenario [DPS] is a low-fidelity simulation technique, used to enhance conflict resolution skills in the emergency room [ER] [1]. In this report, we describe a DPS simulation session in which SPs act as "difficult patients" in the setting of a busy ER. The purpose is to teach junior trainees how to recognize and learn to manage conflict so that they are better able to deal with future encounters with difficult patients.

\section{Categories: Emergency Medicine, Medical Education}

Keywords: simulation, scenario, story, standardized patients, deteriorating patient

\section{Introduction}

Physicians and patients in the ER can often feel conflict with one another. Learners need to recognize and mitigate this early in their patient interactions. In the ER, the pressures of patient acuity and volume necessitate quick conflict resolution. It is common for such unresolved difficulties to progress to verbal and, occasionally, physical threat in the ER. Learning to mitigate dissention is thus essential for a safe and efficient work environment. This contributes in turn to positive patient outcomes [2]. Conflict resolution skills can be taught using didactic lectures, role-playing, and simulation, which utilizes human simulators as well as standardized patients. The choice of delivery will often depend on contextual factors, such as number of students and availability of resources (both simulators and educators). In this technical report, we present a case of adapting a deteriorating patient scenario (DPS) [1] technique to teach conflict resolution skills to senior medical students prior to their Emergency Room rotations. In its original conception, DPS is a low-fidelity simulation activity that provides medical students with opportunities for deliberate practice and feedback. The clinical teacher takes on the role of a patient with deteriorating vital signs. Students have to decide what steps to take in treating or stabilizing the patient, and the case evolves in response to their actions. Throughout the activity, students get the opportunity to compare their thinking to an expert as well as to students that are more senior. During debriefing, students are supported by the teacher in reflection on their actions during the scenario. Because our program utilizes SPs, we have adopted the DPS technique to include SPs.

\section{Local context}

As medical schools redesign curricula to engage students with active learning style preferences,

\section{How to cite this article}

Renouf T, Mitchell K, Hollett S, et al. (August 11, 2014) Deteriorating Patient Scenario for Simulation-Based Training of Difficult Patient Encounters in the Emergency Room. Cureus 6(8): e192. DOI 10.7759/cureus.192 


\section{Cureus}

we have changed the way we approach the academic half-day (AHD). In the past, most of our teaching was didactic. However, we now teach younger students who prefer active and multimedia teaching and learning [3]. Moving to include SPs in a DPS scenario allows the active engagement of learners in developing emergency skills, in this case, conflict resolution skills. Currently, our AHD includes a heterogeneous group of senior medical students $(\mathrm{N}=5)$, junior and senior residents $(\mathrm{N}=6)$, and practicing clinicians $(\mathrm{N}=14)$.

This technical report describes the interaction between learners in the final year of medical school at Memorial University of Newfoundland, and two SPs: a young male patient with back pain whose anger at the wait time in a busy ER either escalates or diffuses depending on the learner's response, and a second SP who acts as a nurse.

The overall learning objectives are to practice conflict resolution skills. Specific learning objectives in this case are:

Identify behaviours that predict difficult patient encounters:

1. Recognize and modify the learner's own negative emotions when provoked,

2. Learn to frame responses objectively, thereby defusing tensions,

3. Understand potential causes of negative patient encounters.

\section{Technical Report}

This simulation is aimed at the final-year undergraduate and PGY-1 learners. Prior to the session, we develop a scenario, which is formulated as a detailed and precise step-wise script (Figure 1).

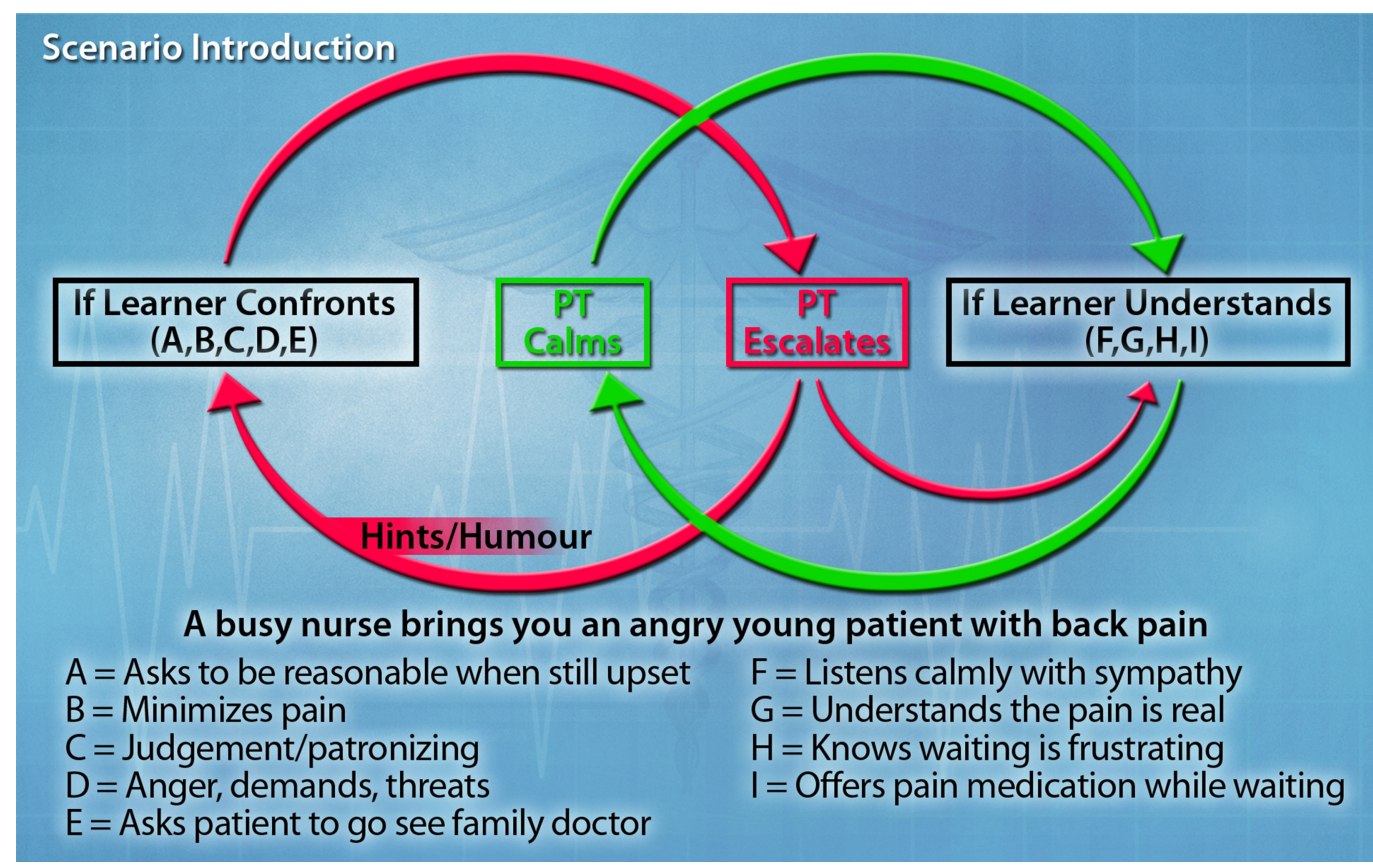

FIGURE 1: This figure depicts the algorithm applied to change the scenario based on the responses from the trainees. 


\section{Cureus}

As previously described, two SPs are recruited to play the patient and a nurse. The video depicts the simulation and highlight the learning obejctives, incorrect, and correct learner responses.

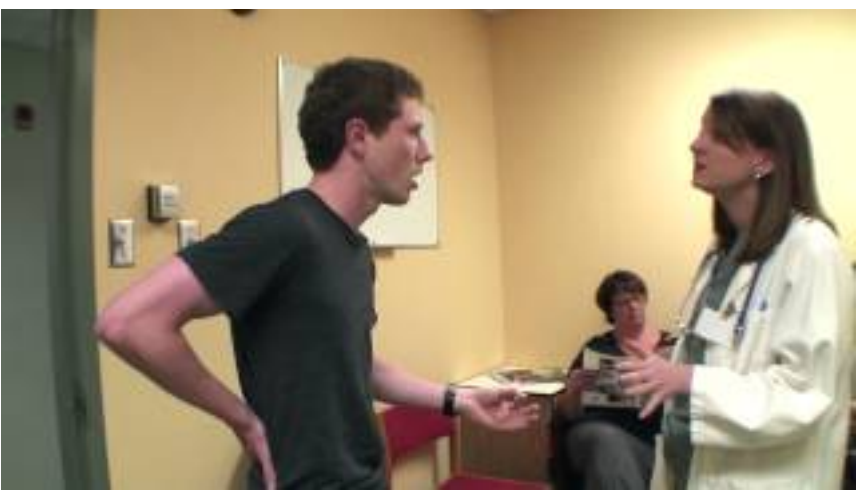

\section{VIDEO 1: Interactions with the difficult patient}

This video demonstrates learning objectives as well as incorrect and correct interactions with the difficult standardized patient.

View video here: http://youtu.be/JbWYdOboyxs

\section{Pre-briefing}

A pre-briefing is held with the learners before the case. The "fiction contract" is discussed and agreed upon; this means that both learners and facilitators recognize that although the exercise is not real, all agree to proceed as though it is. Limitations of the scenario are described [the chaos of a busy ER is not replicated], and trainees are advised that the scenario is strictly formative. The learners are also informed that the "time outs" may be used by learners or facilitators if either thinks the scenario is going off track, for example if the learner is unsure of how to proceed, or deviates from learning objectives by starting to take a patient history.

\section{Case}

\section{Scenario:}

Resident instructions: It is late in the day and the ER is busier than normal. Every exam bed is full, there are patients waiting on stretchers inside the ER and the waiting room is packed. You are about to be approached by Joanne Drover RN, the triage nurse, to assist with a difficult patient. You should not attempt to assess the patient, but merely try to defuse the situation at hand.

\section{Characters:}

SP 1: Dillon Fitzgerald, a 19-year-old male, comes to emergency complaining of low back pain. It has been bothering him for a few days now and he wants it to stop. There is no known trigger for the onset of the pain - there was no recent trauma. The pain is in his lower back and is a dull, achy sensation. It is pretty constant and nothing seems to relieve it. He has taken Tylenol but that has not helped. The pain has neither gotten worse over the past few days, nor does it radiate down his legs or into his feet. He has no other symptoms - he has not been sick or feverish.

SP 2: Joanne Drover, $\mathrm{RN}$, is the triage nurse at the emergency room. It has been a long day. She is doing her best to assess each patient. She first saw Dillon a little over an hour ago and 
determined him to be a low priority. His vitals were all normal.

\section{Background:}

Dillon is restless, agitated, and complaining about how long he has been waiting. He gets up and is pacing around and his voice gets louder as he says he's in pain, questioning what is taking so long. Joanne is standing with a clipboard in her hand when Dillon approaches her. He demands to see the doctor NOW.

Joanne tries to explain that there are a lot of people with more urgent conditions ahead of him but Dillon talks over her in a confrontational fashion (e.g. "Isn't this a hospital? What kind of freaking facility is this?" etc.).

Joanne is getting frustrated and after trying to explain that he must wait, she now tells him he needs to go back and sit down. Dillon persists in his confrontational manner (e.g. "What's your name? Who's your supervisor?" etc.).

This initial encounter lasts one to two minutes.

Joanne walks away and approaches the learner playing the role of the doctor. She asks that s/he come and deal with a patient who is becoming verbally abusive and is creating a scene in the waiting room.

If learner:

1. Calls for security, he will learn that security is dealing with an emergency in the psychiatric ward.

2. Asks for an assistant, he will learn there is none available

The preferred path is to proceed to talk to the patient in an attempt to defuse the angry situation.

\section{Learner Encounter:}

When the doctor approaches Dillon, he believes that the doctor is going to assess and treat him. He starts the interaction using sarcastic comments (e.g. "It's about freakin' time"). He then begins to complain bitterly about his back.

As noted in the resident's instructions, the learner is expected to defuse the situation and not engage in an assessment of the patient's complaints.

If the learner starts to do a patient assessment, the facilitator will directly advise not to assess the patient's problem, just address the angry situation.

Dillon will never be totally pacified, even if the learner performs well. He will continue to display impatience, although he will calm down somewhat and may even start to cry.

Dillon will de-escalate and listen to the learner if the learner:

1. In a calm, understanding tone, acknowledges his distress, 
2. Agrees that waiting a long time while in pain can be very upsetting, and

3. Explains that they have to see patients based on the urgency of their respective situations.

Dillon will escalate and become increasingly confrontational if the learner:

1. Responds with anger,

2. Becomes demanding or threatening in his/her approach to Dillon,

3. Is patronizing or judgmental,

4. Asks or suggests that he be reasonable while he is still really upset,

5. Minimizes his condition or pain,

6. Interrupts his ranting or asks him to stop swearing,

7. Suggests Dillon go and see his family doctor.

Additional Information for the SP:

Dillon has ADHD (Attention Deficit Hyperactivity Disorder) and has a great deal of trouble dealing with anything that stops or slows down his getting what he wants. He has been waiting "patiently" for an hour now. He is immature and not easily able to feel empathy for others, especially when his own needs are not met.

Dillon is not on medication for his ADHD; he uses drugs (primarily cannabis, sometimes oxycodone if he has the money), and alcohol when he has it.

\section{Debriefing}

Debriefing in simulation-based medical education is a well-documented tool shown to increase the effectiveness of learning. Indeed, it is considered one of the most important elements of simulation-based learning [5]. Although in most cases we conduct a formal debriefing at the conclusion of a simulation scenario, performing in a scenario from beginning to end may be challenging for the novice learner. We therefore provide the learners with short feedback cycles embedded within the scenario at each of the potential deterioration points. In addition, a scenario conducted in a group setting where the learner's peers are observing his or her performance may be daunting.

We tailor our debriefing methods on a case-by-case basis. Senior learners may take the scenario from start to finish while more junior learners may opt for timeouts. During these timeouts, we explore difficulties arising during the simulation and allow other group members to discuss alternative techniques that may be useful before proceeding.

Although we typically utilize an advocacy-inquiry approach in formal debriefings, using the plus-delta technique [6] where learners identify positive aspects of an interaction and make notes on aspects they wish to change can be helpful especially with novice learners.

\section{Post-scenario didactics}


A brief didactic is held after the simulation, in order to address any identified knowledge gaps apparent during the session. This allows learners to consolidate the knowledge gained as a result of the exercise.

\section{Discussion}

Recognizing and controlling negative emotions arising in response to difficult patient encounters is an important skill for mitigating and diffusing conflict in the emergency department. Failure to do so allows tensions to escalate, and disrupts communication between physician and patient. The ensuing poor patient communication may in turn lead to medical error [2].

This simulation case is designed to help learners develop a toolbox of words, actions, and body language, which may prove useful in difficult patient encounters. Utilizing simulation in this setting allows them to practice using these tools in a safe environment before transitioning to the real world setting in which potential communication errors may lead to poor outcomes.

In this technical report, we have described a novel adaptation of the DPS technique to be used with SPs in order for the senior medical students and residents to develop a better understanding of skills necessary to resolve conflicts in the ER. The use of the DPS technique allows for planning of events and possible deterioration of the scenario, based on the learners' actions and responses. It also allows structured, formative, and concurrent feedback that is tied to the critical points within the scenario. This is in alignment with recent evidence suggesting that providing more frequent feedback during teaching complex skills to naïve learners may be as critical as providing them with an end-of-scenario debriefing session.

\section{Conclusions}

Simulation is a useful tool for teaching emergency medicine trainees to identify emotional responses to difficult patients. We describe an SP-based simulation, developed to teach learners valuable tools in the mitigation of conflict arising in the emergency department. We utilize low-fidelity simulation, didactics, and some components of debriefing.

\section{Additional Information \\ Disclosures}

Human subjects: All authors have confirmed that this study did not involve human participants or tissue. Animal subjects: All authors have confirmed that this study did not involve animal subjects or tissue. Conflicts of interest: In compliance with the ICMJE uniform disclosure form, all authors declare the following: Payment/services info: All authors have declared that no financial support was received from any organization for the submitted work. Financial relationships: All authors have declared that they have no financial relationships at present or within the previous three years with any organizations that might have an interest in the submitted work. Other relationships: All authors have declared that there are no other relationships or activities that could appear to have influenced the submitted work.

\section{Acknowledgements}

This project was supported by Tuckamore Simulation Research Collaborative and Emergency Medicine Education Committee, Memorial University of Newfoundland. The slide found within this article was designed by Luke Merdsoy.

\section{References}




\section{Cureus}

1. Wiseman J, Snell L: The Deteriorating Patient: A realistic but 'low-tech' simulation of emergency decision-making. The Clinical Teacher. 2008, 5:93-95. 10.1111/j.1743-

498X.2008.00213.X

2. Salas E, Wilson KA, Burke CS, Priest HA: Using simulation-based training to improve patient safety: What does it take?. Jt Comm J Qual Patient Saf. 2005, 31:363-71.

3. Twenge JM: Generational changes and their impact in the classroom: Teaching Generation Me. Med Educ. 2009, 43:398-405. 10.1111/j.1365-2923.2009.03310.x

4. Rudolph JW: Debriefing with good judgment: Combining rigorous feedback with genuine inquiry. Anesthesiol Clin. 2007, 25:361-76.

5. Issenberg SB, McGaghie WC, Petrusa ER, et al.: Features and uses of high-fidelity medical simulations that lead to effective learning: A BEME systematic review. Med Teach. 2005, 27:10-28.

6. Helminski L, Koberna S: Total quality in instruction: A systems approach . Academic initiatives in total quality for higher education. HV Roberts (ed): ASQC Quality Press, Milwaukee, WI; 1995. 309-362. 